\begin{tabular}{|c|l|}
\hline Title & Change in the Morphology of the Terrace Edges on Graphite Surfaces by Electrochemical Reduction \\
\hline Author(s) & Kubota, Shosei; Y onezawa, Tetsu; Nagahama, Taro; Shimada, Toshihiro \\
\hline Citation & $\begin{array}{l}\text { Chemistry Letters, 41(2), 187-188 } \\
\text { https://doi.org/10.1246/1.2012.187 }\end{array}$ \\
\hline Issue Date & 2012-02-04 \\
\hline Doc URL & http://hdl.handle.net/2115/51726 \\
\hline Type & article(author version) \\
\hline File Information & CL41_187-188.pdf \\
\hline
\end{tabular}

Instructions for use 


\title{
Change in the morphology of the terrace edges on graphite surfaces by electrochemical reduction
}

\author{
Shosei Kubota, ${ }^{1}$ Tetsu Yonezawa, ${ }^{2}$ Taro Nagahama, ${ }^{1}$ and Toshihiro Shimada ${ }^{1}$ * \\ ${ }^{1}$ Division of Materials Chemistry, Faculty of Engineering, Hokkaido University \\ ${ }^{2}$ Division of Materials Science and Engineering, Faculty of Engineering, Hokkaido University \\ Kita 13, Nishi 8, Kita-ku, Sapporo, Hokkaido 060-8628, Japan \\ (Received November 30, 2011; CL-111151; E-mail: shimadat@eng.hokudai.ac.jp)
}

We found that graphite surfaces can be etched by electrochemical reduction in sulfuric acid. Terraces with straight edges crossing with $60^{\circ}$-multiple angles were found on surfaces by AFM observation. It suggests that crystallographic edges can be formed at room temperature in a controlled manner. Layer-by-layer etching of graphene sheets was possible by tuning the etching condition.

After the success in separation of single layer graphene[1], graphene-related materials have been studied extensively. Some of the characteristic properties of graphene come from its unique edge states[2]. In order to make use of full-potential of graphene-related materials in electronic devices, edge-defined processing is extremely important. There are two types of edges with low crystallographic indices, i.e., an armchair edge and a zigzag edge. Electronic degeneracy is expected only in zigzag edges, which will lead to unique properties such as characteristic magnetism, ferromagnetism and halfmetallicity[3-6], while armchair edges will show normal electronic dispersion. Thus chemical or physical processes controlling the edge structure as designed are awaited but have not been established so far.

It is predicted that armchair edges are thermodynamically stable[7]. Zigzag edges are only obtained by etching in reductive environment $\left(\mathrm{H}_{2}\right)$ with $\mathrm{Fe}$ clusters at 900 ${ }^{\circ} \mathrm{C}[8,9]$. This technique has a great advantage in making nanoribbons with well-defined edges, but it requires hydrogen environment and high temperature.

In this letter, we explored the possibility of reductive etching in electrochemical environment for the edge-defined processing of graphene. If electrochemical etching is feasible, it does not require high temperature or dangerous hydrogen environment. Although it is reported that AFM oxidization in tip adsorbed water can be used for pattrerning of graphene [10], formed edges were not characterized.

It has long been suggested in Pourbaix diagram that the following reaction is possible in aqueous solution[11].

$$
\mathrm{C}+4 \mathrm{H}^{+}+4 \mathrm{e}^{-} \rightarrow \mathrm{CH}_{4}
$$

It is expected from this reaction that carbon solids can be etched by electrochemical reduction, but this possibility has not been applied to graphene or graphite.

We used highly oriented pyrolitic graphite (HOPG) for the attempt of electrochemical reduction. The specimen size was typically $8 \mathrm{~mm} \times 3 \mathrm{~mm} \times 2 \mathrm{~mm}$ and the surface was cleaved in air by adhesive tape. The HOPG specimen was used as a working electrode, and a $\mathrm{Pt}$ wire and $\mathrm{Ag} / \mathrm{AgCl}$ were used as a counter and a reference electrode, respectively.
These electrodes were immersed in a 10 vol $\% \mathrm{H}_{2} \mathrm{SO}_{4}$ aqueous solution for cyclic voltammetry using HSV-100 (Hokuto Denko) voltammeter. For the reductive etching experiments, conc. $\mathrm{H}_{2} \mathrm{SO}_{4}$ was used in addition to the 10 vol $\% \mathrm{H}_{2} \mathrm{SO}_{4}$. Surface morphologies before and after electrochemical treatment were inspected by AFM (SII SPI $3800 \mathrm{~N})$.

Figure 1 (a) shows cyclic voltammetry (CV) using $\mathrm{HOPG}$ working electrode in 10 vol $\% \mathrm{H}_{2} \mathrm{SO}_{4}$. CV without HOPG (Pt wire only) is shown in Fig. 1 (b) for comparison. When the potential $(E)$ was higher than c.a. $+1.8 \mathrm{~V}$ vs $\mathrm{Ag} / \mathrm{AgCl}$, HOPG turned black and swelled by intercalation of $\mathrm{H}_{2} \mathrm{SO}_{4}{ }^{-}$ derived species and oxidization as reported in Ref.12. Between $+1.5 \mathrm{~V}$ and $0 \mathrm{~V}$ vs $\mathrm{Ag} / \mathrm{AgCl}$, no drastic change was observed by eyes. When the potential was lower than -0.11 $\mathrm{V}$ vs $\mathrm{Ag} / \mathrm{AgCl}$, the current was drastically increased and hydrogen bubbles were observed. As shown in the inset of Fig. 1, a shoulder was observed at $-0.1 \mathrm{vs} \mathrm{Ag} / \mathrm{AgCl}$ when the potential was lowered and a hump was observed at around $+0.2 \mathrm{~V}$ vs $\mathrm{Ag} / \mathrm{AgCl}$ when the potential was increased. The nature of these small structures is unknown because no measuements have been reported in the reduction side of graphite to the authors' knowledge. We speculate that the shoulder and the hump correspond to the reductive etching of carbon or protonation of edges, and deprotonation of edge hydrogen, respecrtively. We note that the former potential is similar to the value suggested from Pourbaix diagram (-0.082 $\mathrm{V}$ vs $\mathrm{Ag} / \mathrm{AgCl})$.

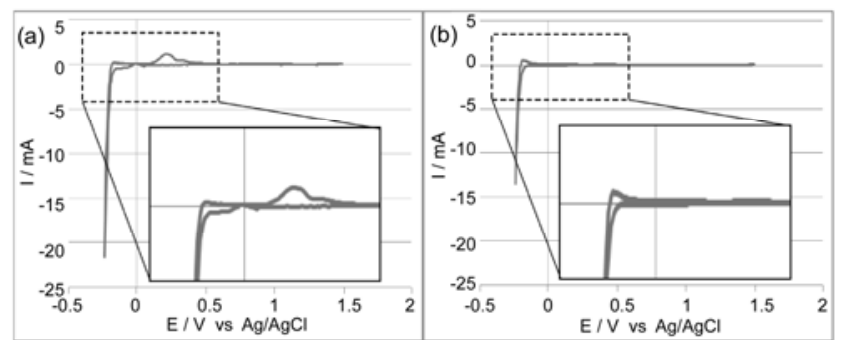

Figure 1. Cyclic voltammogram of $\mathrm{HOPG}$ with $\mathrm{Pt}$ wire (a) and Pt wire only (b) in 10 vol $\% \mathrm{H}_{2} \mathrm{SO}_{4}$.

Figure 2 shows the AFM images before (a) and after (b) electrochemical processing. We applied $-0.20 \mathrm{~V}$ vs $\mathrm{Ag} / \mathrm{AgCl}$ to HOPG working electrode in $10 \mathrm{vol} \% \mathrm{H}_{2} \mathrm{SO}_{4}$ for 20 minutes. The images were taken from the same sample. We obtained many images in wide area of the sample at almost identical positions and we have confirmed that the images shown in Fig. 2 are representative ones before and after the electrochemical reduction. HOPG surfaces after cleavage show no 
characteristic morphology (Fig. 2(a)) and the height difference in $10 \mu \mathrm{m} \times 10 \mu \mathrm{m}$ area was about $30 \mathrm{~nm}$.

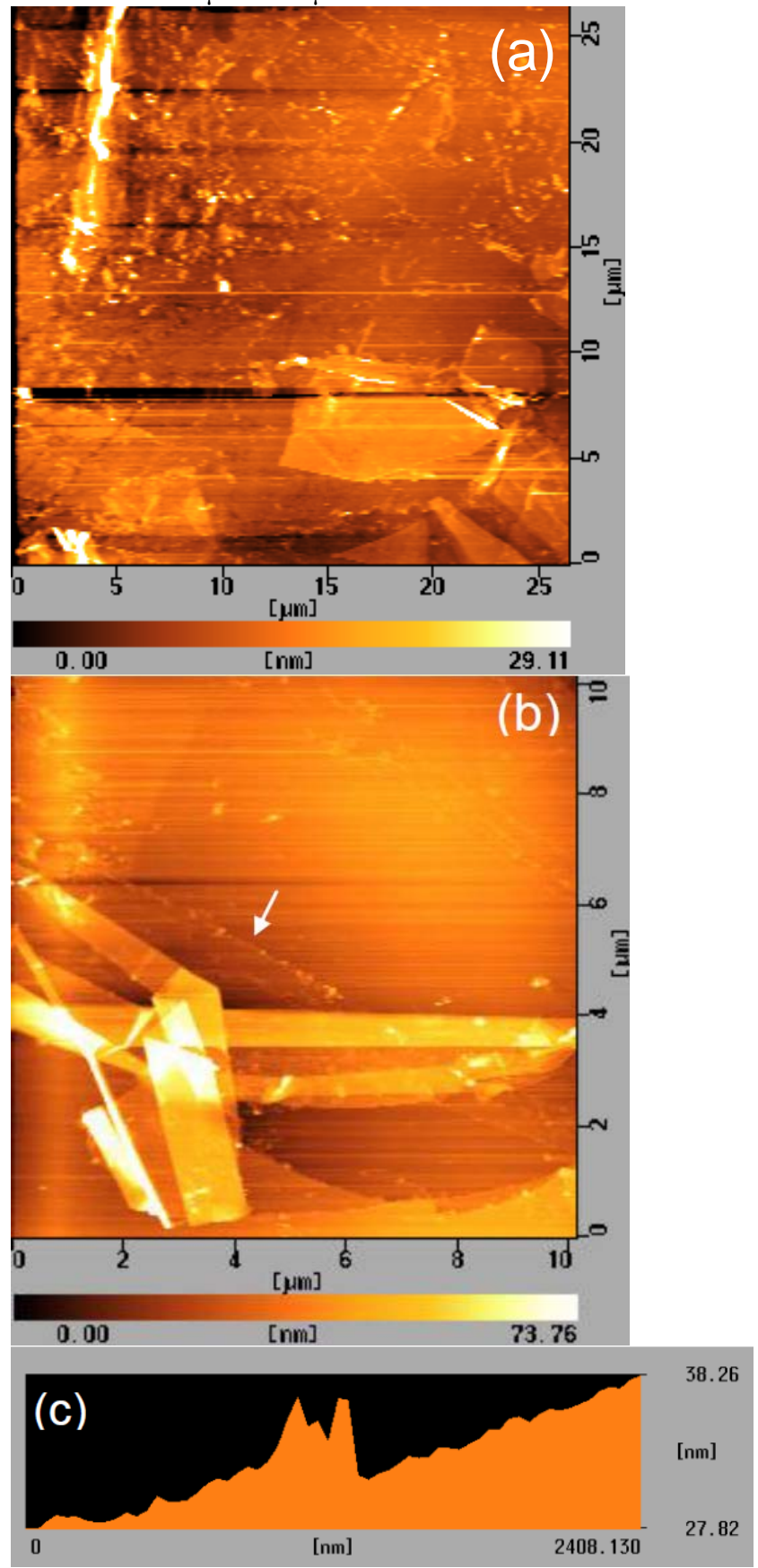

Figure 2. AFM images of cleaved HOPG (a) and HOPG after electrochemical reductive etching. (c) is the cross section plot of the line protrusion indicated by the arrow in (b).

On the other hand, terraces with straight edges were observed after the reduction (Fig.2(b)). The terrace height was $70 \mathrm{~nm}$ at the maximum. The terrace edges cross with each other with characteristic angles that are multiple of $60^{\circ}$. Observation of these characteristic angles strongly suggests that terrace edges correspond to low index crystallographic orientation. A line protrusion was observed in Fig. 2 (b), which is marked with an arrow. This is probably the rolling of graphene sheets during the ething.
Next we examined the effect of using concentrated $\mathrm{H}_{2} \mathrm{SO}_{4}$ as the electrolyte. By electrochemical reduction at the same condition with Fig. 2(b), similar characteristic morphology was obseved (Fig. 3(a)). It is noted that the height difference is far smaller $(5.7 \mathrm{~nm})$ than $10 \mathrm{vol} \% \mathrm{H}_{2} \mathrm{SO}_{4}$ $(74 \mathrm{~nm})$. The cross sectional view shown in Fig. 3(b) indicates the existence of monographene steps $(0.335 \mathrm{~nm})$. It shows the reaction speed can be controlled by the concentration, which is beneficial to the practical processing of graphene and related materials.

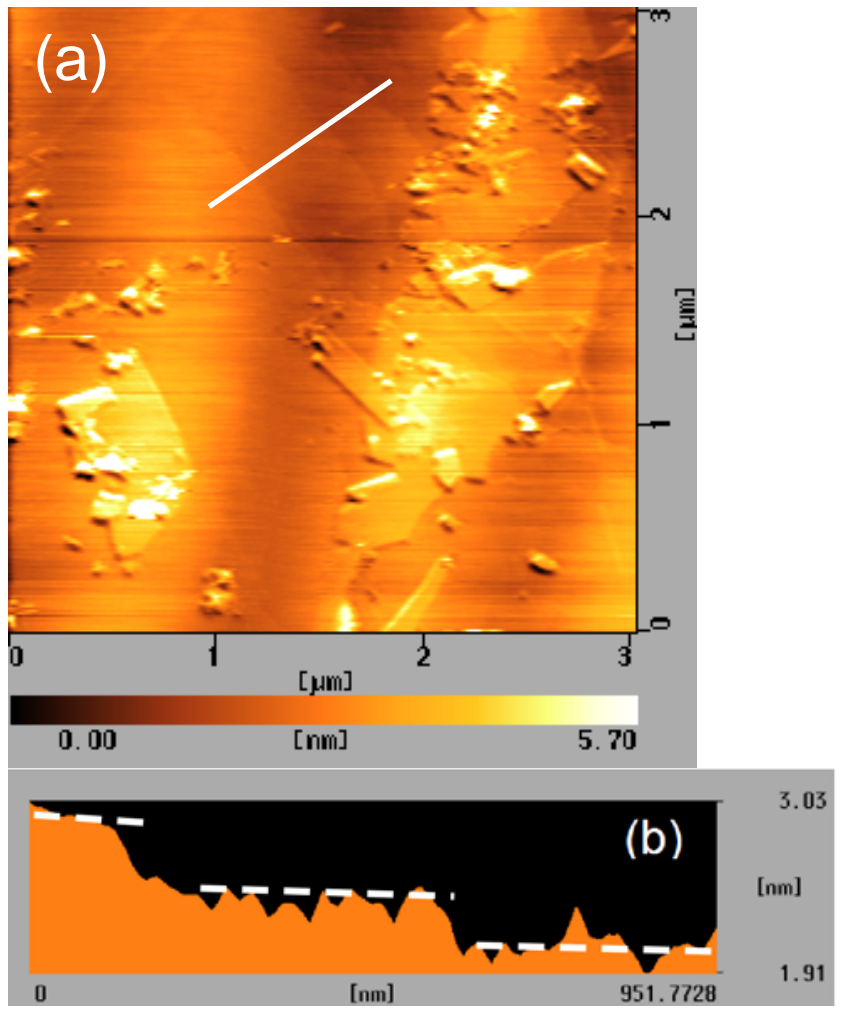

Figure 3. (a) AFM image of HOPG after electrochemical reductive etching in conc. $\mathrm{H}_{2} \mathrm{SO}_{4}$. (b) Cross section view along the line in Fig. 3(a). White dotted lines are guide to eyes indicating layers.

In conclusion, we found that surface morphology of HOPG is drastically changed by electrochemical reduction in $\mathrm{H}_{2} \mathrm{SO}_{4}$. Observation of terraces with straight edges and line protrusion strongly suggests that crystallographic low index edges were prepared by this technique. Single graphene steps were observed by the electrochemical reductive etching in conc. $\mathrm{H}_{2} \mathrm{SO}_{4}$.

\section{References and Notes}

A. K. Geim, K. S. Novoselov, Nat. Mater. 2007, 6, 183

M. Fujita, K. Wakabayashi, K. Nakada and K. Kusakabe, J.Phys.Soc.Jpn. 1996, 65,1920

3 K. Kusakabe, M. Maruyama, Phys. Rev. B 2003, 67, 092406

4 K. Takai, H. Sato, T. Enoki, N. Yoshida, F. Okino, H. Touhra, M. Endo, J.Phys.Soc.Jpn. 2001, 70,175 
Y. Wang, Y. Huang, Y. Song, X. Zhang, Y. Ma, J. Liang, Y. Chen, Nano Lett. 2009, 9, 220

6 O. Hod, V. Barone, J.E. Peralta, G.E. Scuseria, Nano Lett. 2007, 7, 2295

7 L. R. Radovic, B. Bockrath, J.Am.Chem.Soc. 2005, 127, 5917

8 S. S. Datta, Douglas R. Strachan, Samuel M. Khamis, A. T. Charlie Johnson, Nano Lett. 2008, 8, 1912

9 T. Tsukamoto, T. Ogino, J. Phys. Chem. 2011, 115, 8580

10 N. Yoshimizu, B. Hicks, A. Lal, C. R. Pollock, Nanotechnology 2010, 21, 1

11 Pourbaix M 1974 Atlas of Electrochemical Equilibria in Aqueous Solutions $2^{\text {nd }}$ edn (New York: National Association of Corrosion Engineers) pp 449-57

12 J. Fiang and F. Beck, Carbon 1992, 30, 223-228 
NOTE The diagram is acceptable in a colored form. Publication of the colored figures are free of charge.

For publication, electronic data of the colored G.A. should be submitted. Preferred data format is EPS, PS, CDX, PPT, and TIFF. If the data of your G.A. is "bit-mapped image" data (not "vector data"), note that its print-resolution should be $300 \mathrm{dpi}$.

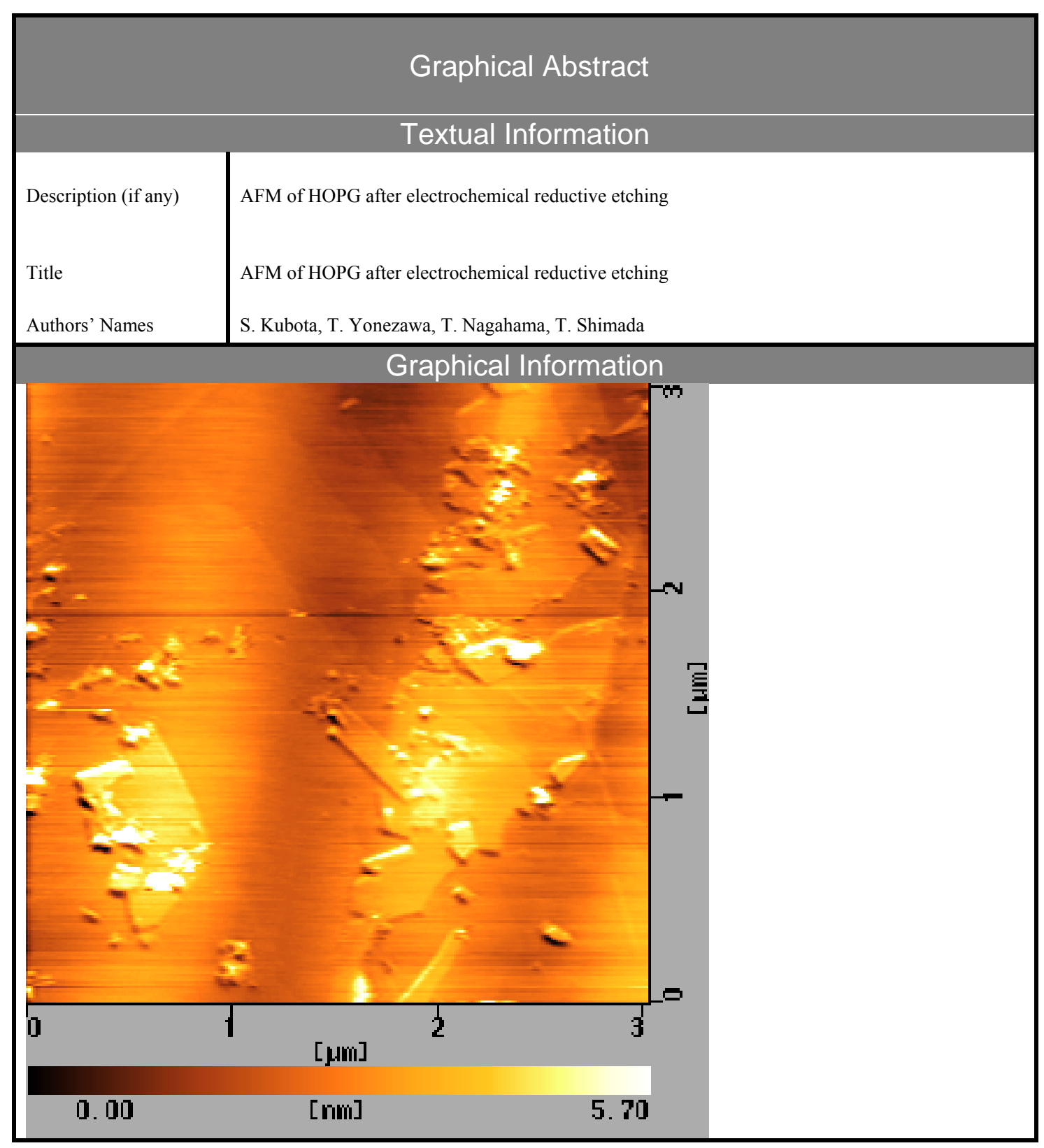

